\title{
EXPLORING SYSTEMIC FORCES THAT INFLUENCE SUSTAINABLE DESIGN TRANSITIONS
}

\author{
Watz, Matilda (1); \\ Hoffenson, Steven (2); \\ Hallstedt, Sophie. I. (1) \\ 1: Blekinge Tekniska Högskola; \\ 2: Stevens Institute of Technology
}

\begin{abstract}
In this research some systemic forces to sustainable design are described and mapped out, along with key areas, dimensions and stakeholders. These results are visualized in a causal loop diagram (CLD), which was the outcome of a group model building approach supported by a literature review. Within the proposed system model, represented by the system-level variables and their relationships within the CLD, some potential leverage points that can help make product design better contribute to sustainability are identified and described. These can be found in the balancing and reinforcing feedback loops of the CLD as well as the mapping to societal dimensions of sustainability transitions and stakeholder groups. Among the stakeholder groups, business managers, scientific researchers and engineering designers can be tied to the design community. Future research is proposed to build on these initial results to deepen the knowledge about the systemic drivers and barriers and leverage the contribution of design practice to sustainable development.
\end{abstract}

Keywords: Sustainability, Decision making, Complexity, Sustainable product development; Causal loop diagram

\author{
Contact: \\ Watz, Matilda \\ Blekinge Tekniska Högskola \\ Sweden \\ matilda.watz@bth.se
}

Cite this article: Watz, M., Hoffenson, S., Hallstedt, S. I. (2021) 'Exploring Systemic Forces that Influence Sustainable Design Transitions', in Proceedings of the International Conference on Engineering Design (ICED21), Gothenburg, Sweden, 16-20 August 2021. DOI:10.1017/pds.2021.411 


\section{INTRODUCTION}

Industry, and particularly the manufacturing industry, is a profound contributor to our common sustainability challenges. However, in a sustainable future scenario, products will still be needed, either in the shape of pure artefacts or as part of combined, perhaps digitalized, product-service system solutions (Opazo-Basáez et al., 2018; Hoffman et al., 2019; Hojnkik, 2018). New products, technologies and services are required to contribute to a sustainable development to realize a transition to sustainability. To do so, product innovation must increase integration of sustainability considerations into the design rationale, see e.g., Ceschin (2016). This leads to a challenge in identifying key actors and areas in the socio-ecological system which product development should address to leverage sustainable development, see e.g., Gagnon et al. (2012); Miedzinski et al. (2019). Several initiatives such as cleaner production, ecodesign, and recently, circular economy, provide valuable ideas and examples for how industry can use social and ecological criteria as value drivers in their businesses. To aid product developing companies, several methods, strategies and tools have been developed which aim to help designers and decision-makers in the product innovation process in identifying sustainability criteria, and to integrate these into traditional decision support tools (Bovea \& Pérez-Belis, 2012). The approaches include simplified lifecycle assessments, and sustainabilityadaptations of quality-function deployment, concept-selection matrices, technology readiness-levels, material selection guides, and sustainability compliance indices, to mention a few (Watz \& Hallstedt, 2018).

Unfortunately, the shift from business as usual is often too slow, and the strategies, methods and tools for sustainable design are seldom implemented by companies (Faludi et al., 2020). In addition, to realize a sustainability transition, product development needs to adopt a systemic (Bengtsson et al., 2016) and strategic (Baumgartner, 2016) sustainability perspective instead of continuing in the paradigm of incremental improvement and efficiency of sustainability aspects (Dyllick and Rost, 2017). Radical systemic shift requires that interdependencies between different system dimensions and stakeholders are increasingly considered. Deepening our awareness and understanding of these interactions might enable areas of interdependency to act as leverage points and thus to cascade local changes throughout the system. To do so, product development companies must increase their capabilities, in terms of both know-how and decision support, to capture and integrate social and ecological criteria that go beyond regulatory compliance using a systems perspective (Watz and Hallstedt, 2020). In the light of this background, this research seeks to explore two questions: What are the systemic forces that serve as drivers and barriers to sustainable design?, and among those, What are the key systemic leverage points that can make product design better contribute to sustainability? The objectives are threefold, namely to (i) identify, describe and organize systemic variables and mechanisms in society that influence the adoption of sustainable product development approaches and thereby sustainability improvements, (ii) discuss and map how these are related, and (iii) identify key societal dimensions and stakeholders along with their opportunities to make change within the proposed system. Through this, we aim to provide product developing companies with a platform for increased capabilities to capture and address societal and ecological needs in early design phases and to create common solutions in the value chain to speed up the development of sustainable design solutions.

\section{RESEARCH APPROACH}

The research questions are addressed with a group model building (GMB) approach that is supported by a literature review, resulting in a causal loop diagram (CLD). GMB is a useful method for collaborative learning and creation of decision support in complex systems (Vennix, 1999) and has become well-used within sustainability research (Hjort \& Bagheri, 2006; Fiksel, 2006). GMB is traditionally organized in five steps (Andersen et al., 2007). CLDs can be used in the first two steps during which the participants together define the problem, including (1) identification of systemic variables, and (2) formulation of a dynamic hypothesis. This second step qualitatively illustrates how the variables influence one another and the general behaviors within the system. Reinforcing and balancing relationships as well as delayed feedback can be visualized with standard symbols, which will be described in the next section. In step (3), stock-and flow functions can be defined for the relationships between the CLD variables, creating a system dynamic (SD) simulation model. Step (4) involves model testing, allowing for smaller modifications, and step (5) involves policy design and 
evaluation (Andersen et al., 2007). Although SD models provide the opportunity to simulate policy interventions, both CLDs and SD models can be used to identify leverage points, i.e., where to intervene in the system to improve its performance. Since the goal for the participants, who may come from different backgrounds, is to build and agree on a common model, the construction of a CLD generally requires several modeling iterations. In this way they may learn from other participants' perspectives of the system and transparently co-create a decision support (Coyle, 2000).

This research applied the first two steps of the general GMB process, which will be continued in a second research phase. In a total of ten modelling iterations, the three authors co-created a CLD that captures the key factors that connect engineering design to sustainability outcomes, based on their prior knowledge and expertise in the area of sustainable design and product development, while guided by key literature through a general extended literature review (Thomas and Hodges, 2010). A reference framework for key societal dimensions of sustainability transitions (Miedzinski et al., 2019) is adopted to ensure that the CLD covers key areas and stakeholders.

\section{SYSTEMIC FORCES THAT INFLUENCE SUSTAINABLE DESIGN}

The CLD emerged, and was continuously revised and refined, during the iterative modelling sessions, using input from the researchers' experience and the literature review. The thirteen system-level variables (V1-V13), represent the qualitative factors which were identified, and the arrows indicate how they are interrelated and influence one another. The CLD provided in Figure 1 outlines the variables and links as a result of the iterative GMB process. Thereafter follows a description of the CLD along with a list of variable definitions and supporting literature in Tables 1 and 2.
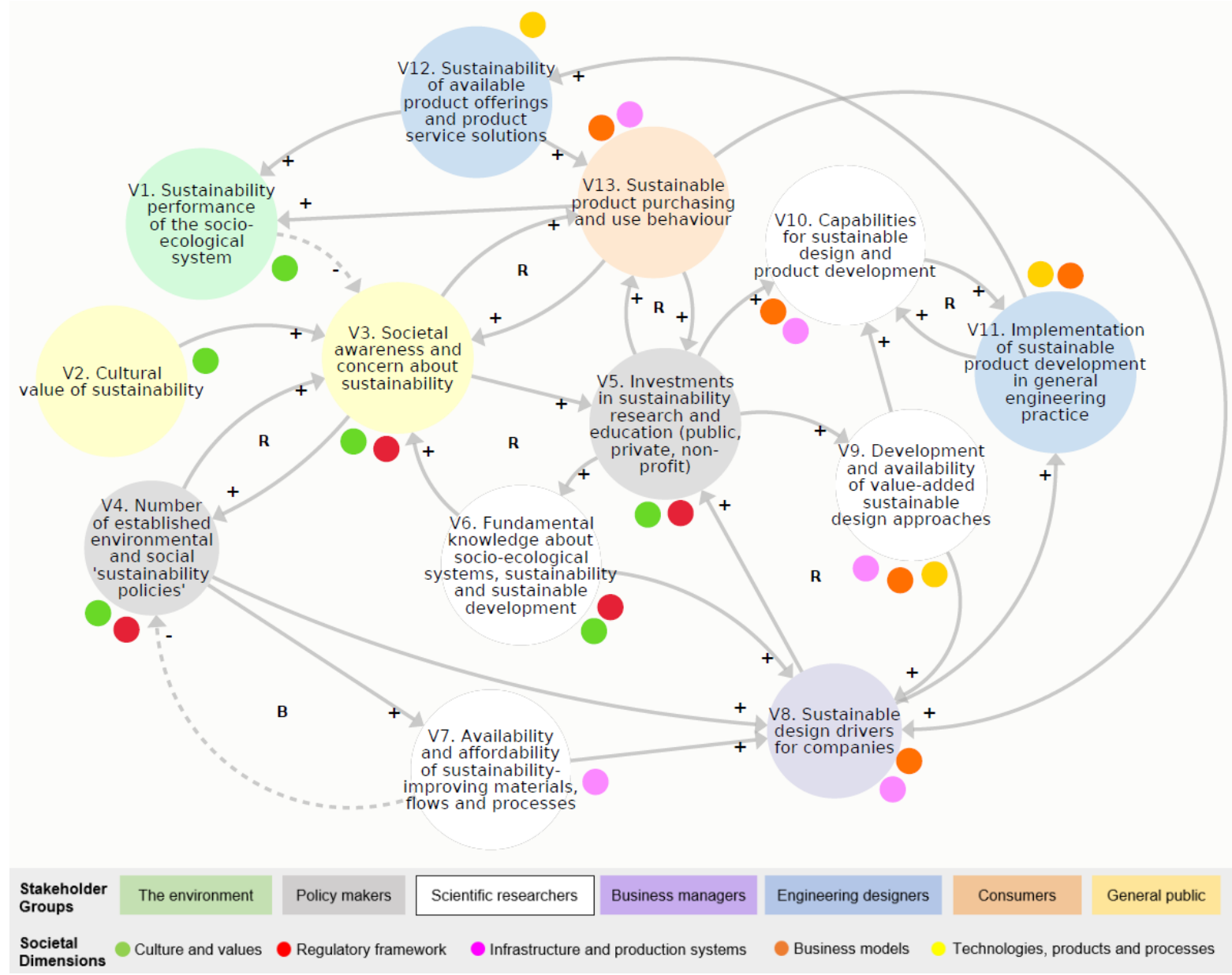

Figure 1. Causal loop diagram (CLD) resulting from iterative group model building (GMB) process. The variable colours, and the neon dots, refer to the stakeholders and societal dimensions identified in section 4 ,

The variables, which at this stage represent high-level phenomena, are defined in such a way that they can increase or decrease depending on the influence of another variable. A positive $(+)$ arrow indicates 
that the variables change together in the same direction, i.e., an increase in variable ' $\mathrm{X}$ ' leads to an increase of variable ' $\mathrm{Y}$ ', whereas a negative (-) arrow indicates that they change in opposite directions. Positive and negative arrows in the diagram, hence, do not correspond to 'increase' or 'decrease', but can be understood as 'same' or 'opposite'. For example, the positive arrow between V11 and V12 is to be understood as 'when the implementation of sustainable product development in general engineering practice increases (or decreases), sustainability performance of available product offerings and service solutions also increases (or decreases)'. The negative arrow between V7 and V4 describes that 'when the availability and affordability of sustainability-improving material flows and processes increases (or decreases), the number of established environmental and social sustainability policies oppositely decrease (or increase)'. A looping ' $\mathrm{R}$-arrow' in the diagram indicates a reinforcing relationship between its connected variables, while a looping 'B-arrow' indicates that the relationship is balancing. A reinforcing loop can act as either a driver or a barrier, depending on how the variables in that loop change, whereas a balancing loop can be seen as a mechanism that maintains the status quo.

Table 1. CLD variable definitions and supporting literature, part 1.

\begin{tabular}{|c|c|}
\hline Variable & Description (example references in italic) \\
\hline $\begin{array}{l}\text { V1. Sustainability } \\
\text { performance of the } \\
\text { socio-ecological } \\
\text { system. }\end{array}$ & $\begin{array}{l}\text { Sustainability can be described as a state of balance in, and between, the } \\
\text { Earth's socio-ecological systems. This can be defined using overarching } \\
\text { socio-ecological sustainability principles. Sustainable development can be } \\
\text { understood as progress towards this state. } \\
\text { Steffen, W., et al. (2015); Broman, G. I., \& Robèrt, K. H. (2017). }\end{array}$ \\
\hline $\begin{array}{l}\text { V2. Cultural value of } \\
\text { sustainability. }\end{array}$ & $\begin{array}{l}\text { The cultural value of sustainability is related to the existing social norms } \\
\text { and the historical connection between the people and nature. } \\
\text { Tata, J., \& Prasad, S. (2015) }\end{array}$ \\
\hline $\begin{array}{l}\text { V3. Societal awareness } \\
\text { and concern about } \\
\text { sustainability. }\end{array}$ & $\begin{array}{l}\text { The general level of knowledge, concern, and desired/intended } \\
\text { sustainability action by the public and key stakeholders. } \\
\text { Korotkova, A. V. (2020); Nagaichuk, N., et al. (2020) }\end{array}$ \\
\hline $\begin{array}{l}\text { V4. Number of } \\
\text { established } \\
\text { environmental \& social } \\
\text { 'sustainability policies'. }\end{array}$ & $\begin{array}{l}\text { The presence and stringency of measures and initiatives, on local, regional } \\
\text { and global scales, targeting sustainable development. Examples include } \\
\text { environmental law, market regulations, trade or sector agreements, } \\
\text { directives, standards, reporting initiatives and labels. } \\
\text { Köhler, J., et al. (2019) }\end{array}$ \\
\hline $\begin{array}{l}\text { V5. Investments in } \\
\text { sustainability research } \\
\text { and education (public, } \\
\text { private, non-profit). }\end{array}$ & $\begin{array}{l}\text { Public, private, and non-profit entities invest in research projects to increase } \\
\text { knowledge about socio-ecological systems and capabilities to facilitate } \\
\text { sustainable development. Research funding is provided both to basic } \\
\text { sciences, i.e., natural science and social sciences, and to applied sciences, } \\
\text { such as sustainable technology, transdisciplinarity and governance as well } \\
\text { as economics and business models. Sustainability is also introduced and } \\
\text { taught in education at various levels and disciplines. } \\
\text { Köhler, J., et al. (2019); Lozano, } R . \text { et al. (2015) }\end{array}$ \\
\hline $\begin{array}{l}\text { V6. Fundamental } \\
\text { knowledge about socio- } \\
\text { ecological systems, } \\
\text { sustainability, and } \\
\text { sustainable } \\
\text { development. }\end{array}$ & $\begin{array}{l}\text { Knowledge about the status of natural resources and human society, i.e., the } \\
\text { ability of the environment and society to provide the necessary conditions } \\
\text { for a healthy planet with fair living conditions, now and long-term. This is } \\
\text { also knowledge and know-how about technology, business models and } \\
\text { governance that can support sustainable development. } \\
\text { Miller, T. R. (2013) }\end{array}$ \\
\hline
\end{tabular}

The CLD describes that the status of the Earth's socio-ecological system, i.e., its health and ability to sustain over time, can be understood as its sustainability performance (V1). While the performance of the ecological system depends on the pressures and impact from society, see e.g., the planetary boundaries, the functioning of the social system depends on how society itself is organized. Human systems, such as economy, welfare and political structures, affect access to nature as a resource, the conditions for individuals to live good lives, and through those, the conditions for companies to operate. Sustainability in the socio-ecological system is influenced by the manufacturing, adoption and 
use of products and technologies that we use in our society, along with their socioecological lifecycle impacts (V12, V13). Awareness and concern about sustainability (V3) is a response to changing behaviour of nature and society, i.e., changing socio-ecological system conditions that challenge the ability to meet the needs of society. As a consequence, more investments in sustainability research are made (V5) in different domains of society, including public, business, non-profit, and nongovernmental institutions. These research investments lead to results that increase our shared knowledge about socio-ecological systems and sustainability (V6), which in turn may increase the societal sustainability concern even more (V3). An important factor, however, is the cultural value of sustainability in the society (V2), which might constrain or enforce the sustainability concern, thus regulating the desire to invest in research and policymaking for sustainable development.

Table 2. CLD variable definitions and supporting literature, part 2.

\begin{tabular}{|c|c|}
\hline Variable & Description (example references in italic) \\
\hline $\begin{array}{l}\text { V7. Availability and } \\
\text { affordability of } \\
\text { sustainability-improving } \\
\text { materials and flows and } \\
\text { processes. }\end{array}$ & $\begin{array}{l}\text { Sustainable materials and manufacturing processes are critical to a } \\
\text { sustainability transformation, especially their availability (existence and } \\
\text { widespread access) and affordability (competitive costs). } \\
\text { Köhler, J., et al. (2019) }\end{array}$ \\
\hline $\begin{array}{l}\text { V8. Sustainable design } \\
\text { drivers for companies. }\end{array}$ & $\begin{array}{l}\text { Companies are driven by their core values and external incentives. } \\
\text { Sustainable design drivers include direct demand from customers/users, } \\
\text { design and manufacturing capabilities, the policy environment, } \\
\text { shareholders'/owners' values, and internal demand from employees. } \\
\text { Laurenti, R., et al. (2016); Dyllick, T., \& Muff, K. (2016) }\end{array}$ \\
\hline $\begin{array}{l}\text { V9. Development and } \\
\text { availability of value- } \\
\text { added sustainable } \\
\text { design approaches. }\end{array}$ & $\begin{array}{l}\text { The development and availability of actionable processes, methods, and } \\
\text { tools that encourage sustainable design, and which are available, effective, } \\
\text { and easy for industry to use and implement. Ceschin, F., \& Gaziulusoy, I. } \\
\text { (2016); Faludi et al. (2020) }\end{array}$ \\
\hline $\begin{array}{l}\text { V10. Capabilities for } \\
\text { sustainable design and } \\
\text { product development. }\end{array}$ & $\begin{array}{l}\text { Industrial and academic knowledge, skills and competency about how to } \\
\text { design for sustainability. } \\
\text { Karlsson, R., \& Luttropp, C. (2016); Hallstedt, S. (2008) }\end{array}$ \\
\hline $\begin{array}{l}\text { V11. Sustainable } \\
\text { product development in } \\
\text { general engineering } \\
\text { design practice. }\end{array}$ & $\begin{array}{l}\text { The maturity level of sustainable design implementation, in terms of } \\
\text { systematic implementation in product development management structures, } \\
\text { as well as organizational know-how and culture, enables sustainability } \\
\text { integration into engineering requirements and business strategy } \\
\text { development. } \\
\text { Watz, M., \& Hallstedt, S.I., (2020); Hallstedt, S. I., Thompson, A. W., \& } \\
\text { Lindahl, P. (2013); Pigosso, D. C., \& McAloone, T. C. (2016) }\end{array}$ \\
\hline $\begin{array}{l}\text { V12. Sustainability of } \\
\text { available product } \\
\text { offerings and product } \\
\text { service solutions. }\end{array}$ & $\begin{array}{l}\text { The share of a company's product offerings with comparatively positive } \\
\text { social and ecological impact, as well as the actual sustainability } \\
\text { performance of those offerings (including economic value). Along with } \\
\text { competitors' product offerings, this product stream feeds into the } \\
\text { sustainability level of product and service offerings at the market. } \\
\text { Bengtsson, M., et al. (2018); Dyllick, T., \& Rost, Z. (2017) }\end{array}$ \\
\hline $\begin{array}{l}\text { V13. Sustainable } \\
\text { product purchasing and } \\
\text { use/behaviour. }\end{array}$ & $\begin{array}{l}\text { How customers interact with products, including their selection of more or } \\
\text { less sustainable options to purchase and the ways that they later use those } \\
\text { products (e.g., higher or lower energy consumption, or length of first use } \\
\text { cycle). } \\
\text { Fargnoli, M., et al. (2018) }\end{array}$ \\
\hline
\end{tabular}

The knowledge about socio-ecological systems and sustainability can also be used in applied research leading to development and increased availability of sustainable design methods and tools that add business value, which can be economic or allude to corporate values (V9), and to the organizations that decide to implement them (V11), increasing known triggers to sustainable design in companies (V8). For a business to be successful while contributing to a sustainability transition, increased 
knowledge about socio-ecological systems and sustainability is required. This helps identifying and improving the availability and affordability of sustainability-improving material flows and processes (V7), which is another driver for sustainable design in companies (V8). Combined with better understanding of the characteristics and business benefits of products which contribute to sustainability, these aspects together grow capabilities for sustainable design and product development (V10). Increased societal awareness (V3) also leads to the development and ratification of environmental and social sustainability policies, laws and regulations, including but not limited to initiatives such as mandates for minimum sustainability performance, sustainability labelling, certification and standards institutes, and global reporting (V4). Together with a growing concern about sustainability, which may increase the purchasing and use of sustainable product-service offerings in society, a direct driver for more sustainable design development in companies (V8), the affordability of sustainability improving material flows and processes can increase further (V7).

Once drivers for sustainable design have been identified and acknowledged by product developing companies, the methods and tools for sustainable design together with new knowledge about sustainability-improving material flows and processes can drive the development and manufacture of product (and service) offerings (V12), from which consumers can then choose to purchase and use in more or less sustainable ways (V13), thereby influencing the sustainability performance of the socioecological system (V1).

\section{KEY AREAS INFLUENCING THE SOCIETAL DIMENSIONS OF SUSTAINABILITY TRANSITIONS}

The CLD in Figure 1 illustrates the proposed systemic relationships among key variables, the relationships among them, sustainability factors and their proliferation of sustainable design practices. Now, to achieve a systemic change in society requires that all societal dimensions are aligned towards the same objectives (Miedzinski et al., 2019). Therefore, these system dimensions need to be identified, and their challenges must be understood to motivate a change. Also, stakeholders need to be defined to enable a discussion about suitable measures to undertake in the system. While these societal dimensions and stakeholders were previously indicated with colour coding in Figure 1, they are detailed and justified in this section.

Previous research has presented societal dimensions of sustainability transitions. For example, Miedzinski et al. (2019) define five societal dimensions: 1) cultures and values; 2) regulatory framework; 3) infrastructure and production systems; 4) business models; and 5) technologies, products, and processes. Our CLD proposes thirteen interlinked variables which represent key areas that together cover these five societal dimensions. In addition to the system variables and societal dimensions, seven key stakeholder groups were identified: i) the environment, ii) policy makers, iii) scientific researchers, iv) business managers, v) engineering designers, vi) consumers, and vii) general public (including macro-level societal structures to local communities). The CLD visualizes that stakeholders from each of the key areas indirectly can influence adoption of sustainable product development and design practices that contribute to sustainable development. This is through the nested interdependencies between the stakeholders and the activities within each area and in each societal dimension. These interdependencies may allow one change to cascade through the entire system, facilitating the identification of leverage points throughout the system that have the potential for systemic shifts.

Figure 2 (see next page) illustrates how the 13 variables of the CLD map to the five societal dimensions. Although the variables likely are influenced by several stakeholder groups, a key stakeholder has been selected for each variable. This provides a starting point for future primary stakeholder research to better understand the mechanisms for change. The stakeholder groups were selected with consideration of their motivating factors, barriers, and decision-making capacities.

- Technologies, product, and processes: The key stakeholders in this dimension are scientific researchers, who may be academic or industry-based, and engineering designers, who typically work for product producing companies. Currently, sustainable product design in companies is limited by the availability of value-added sustainable design methods and tools, material and process options, and a lack of sustainability incorporation into general design practice. Many of these limitations can be advanced through research or proactive government or corporate policies. The outcomes of these decisions lead to products designed and offered in the 
marketplace, which may be more or less sustainable. Early innovation and management decisions have a major impact on the product life cycle, including production and resource flows. Sustainability criteria should therefore guide design decisions rather than be limited to assessing sustainability compliance to design decisions that already have been made.

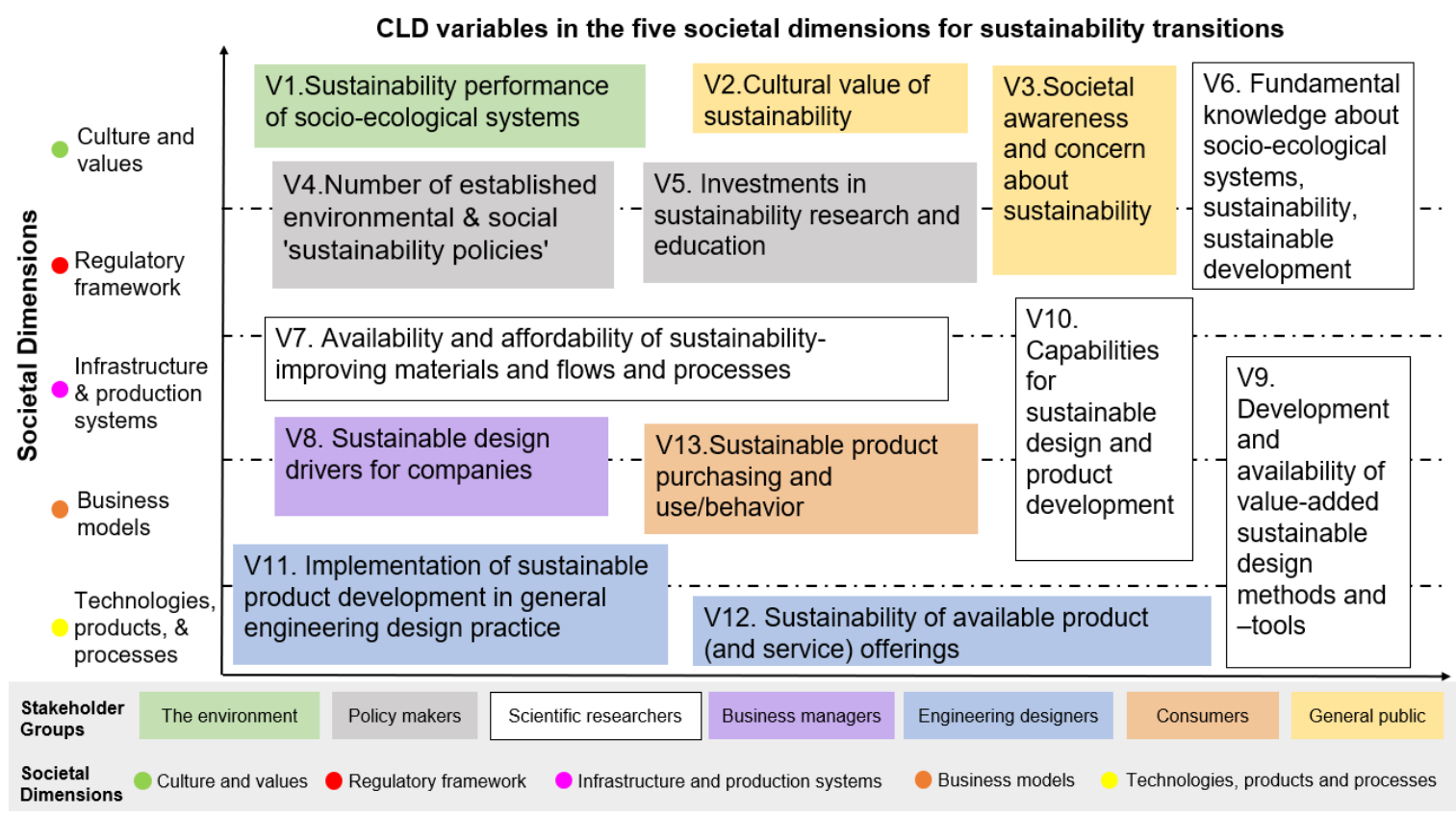

\section{Figure 2. Mapping of CLD variables to the five societal dimensions of sustainability transitions and key stakeholder groups}

- Business models: This dimension corresponds with the right-side variables of the CLD in Figure 1 , and it accounts for the actions and behaviours of business managers, designers, researchers, and consumers. Management sets high-level product strategies, researchers advance what is possible through sustainable design approaches, designers implement strategies using available methods to create products, and consumers respond to the available product offerings in a way that influences future product strategy. Business models are influenced by government policy and research progress, and they directly lead to the sustainability of products on the market and sustainability performance. However, corporate values can also play a substantial role in driving or hindering sustainable design strategy and progress.

- Infrastructure and production systems: This dimension is shaped by scientific researchers, who advance what is possible in materials, processes, and methods; business managers, who determine their product and production strategies and investments; and consumers, whose demand for products leads to shifts in production capacity needs as well as future product strategy. Available infrastructure and production systems often serve as an economic barrier to making significant shifts in product design over previous iterations.

- Regulatory framework: Government policy plays a direct role in advancing sustainable products and sustainability research; this can be implemented through direct funding, monetary incentives, or mandates. Such policies can lead to research advances that result in more sustainable materials, processes, or methods, as well as direct sustainable design drivers for companies.

- Culture and values: In democratic societies, regulatory frameworks are theoretically influenced by the will of the people, making the general public a driver for new or improved policies. Furthermore, consumer purchasing behavior, which is influenced by culture and values, can shift business priorities and thereby design strategies. Society's culture and values are influenced by the state of sustainability in society, e.g., if there are no pressing environmental concerns, values may be focused on social or economic areas, as well as the fundamental knowledge about socioecological systems. Therefore, advancing our fundamental knowledge and creating a culture that values scientific understanding can play a major role in advancing sustainability through design. 


\section{DISCUSSION AND FUTURE WORK}

Triggering systemic shifts across multiple societal dimensions is complex, as there may be different levels of resistance to change within different areas of the system. That is why the concept of leverage points, which may be intervened upon to act as drivers and barriers, is critical in the discussion about how different actors within the socio-ecological system can contribute to sustainable development (Hjorth and Bagheri, 2006). Although some actions or changes to the conditions within one area of the system might generate a positive effect, it might only be incremental. Achieving systemic transition to sustainability requires that radical shifts take place within the areas that can influence several societal dimensions at the same time and in the same direction (Miedzinski et al., 2019). In the current model, systemic forces are depicted as variables, while 'leverage points' can be understood as specific variables in the context of balancing or reinforcing feedback loops. For example, variables 3,5 , and 6 create a positive reinforcing relationship of sustainability research, knowledge, and awareness that together may fuel the development and adoption of sustainable design approaches within companies. The only balancing loop, between variables 4 and 7, on the contrary indicates how the availability of sustainable materials may reduce regulatory measures, demonstrating a well-known barrier to increased sustainability improvement within product design. Although only one balancing loop was defined in the current CLD iteration, more sources of inertia in the system may later be unravelled and discovered among the other variables. In this way, we hope to guide a continued discussion and journey towards better knowledge about the sources of inertia that are embedded in the current system, which have identified several promising reinforcing leverage points that may serve as drivers for sustainable design.

The goal of this paper is therefore that this CLD may reveal and help unravel some of the complexities within this system, guide a continued discussion about which efforts need to be made, and by whom, and thereby accelerate the contribution of product development to a sustainability transition. Product developing companies and design researchers can use this initial system models as a foundation for continued discussion on which measures product design and development should take to leverage systemic sustainability, including which stakeholder collaborations might need to be initiated or further developed. This will inform and enable the design community to act upon identified forces for accelerating a transition to sustainable design.

In the next stages of this research, we suggest that the identified variables of the proposed CLD and their systemic relationships are confirmed, or otherwise revised, according to input from representatives of each of the key stakeholder groups. Starting with this initial CLD, semi-structured interviews with key stakeholders can provide first-hand, empirical input and refinements to our system understanding. This may unravel additional variables and leverage points, and importantly, a more detailed understanding of sources of inertia in the system. This could generate a deeper awareness of not only the value driving forces, but also awareness of the balancing feedback mechanisms which currently serve as barriers to systemic sustainable design.

Among the key stakeholders, the design research community contains members that include business managers, scientific researchers and engineering designers. Therefore, future research within the design community can focus on deepening the understanding of the variables and systemic relationships that can be linked to these three stakeholder groups. One immediate next step is for scientific researchers to interview and survey business managers and engineering designers to address the following questions:

- How does sustainability fit into design requirements, and how can it fit in the future?

- What factors are viewed as "trading off" with sustainability?

- In what ways do capability limitations (e.g., lack of more sustainable material or process options, lack of ability to quantify trade-offs among economic, environmental, and social impacts) influence the sustainability profile of your products and services?

- In what ways do historical data on consumer purchasing influence the design process? Does this limit or drive the sustainability level of your products?

- In what ways do projections of consumer purchasing behaviour influence the design process?

- How do you measure the sustainability of your products?

To further scrutinize identified relationships that may remain unclear or that are determined as critical barriers to address, a design structure matrix could add value in better understanding the interconnected nature of some of these specific variables. Thereafter, a quantification of the modelled 
drivers and barriers, and their systemic relationships, can provide the opportunity for stakeholders to simulate the effect of interventions in the system. This could lead to effective interventions, i.e., that identified actions are directed to the leverage points which pave the way for sustainable design at systemic scale.

\section{CONCLUSIONS}

In this paper we have identified systemic forces in society that influence the adoption and evolution of sustainable product design and development. The results of a group model building approach, supported by a literature review, are variables and mechanisms, visualized in a causal loop diagram (CLD) that outlines key areas, dimensions and stakeholders within the proposed system. In this way we have revealed some potential systemic forces that serve as drivers and barriers to sustainable design, presented as the system-level variables and their corresponding reinforcing and balancing relationships within the system model. In addition, we have mapped the variables to societal dimensions and stakeholder groups that together can help make product design better contribute to sustainability. Future research will focus on validating and detailing the understanding of the identified areas and stakeholders, which can enable simulations of system interventions that can be used as decision support within, and between, the stakeholder groups.

\section{ACKNOWLEDGEMENTS}

Sincere thanks to the Erasmus+ mobility program which enabled this transatlantic research collaboration. A portion of this study was funded by the Knowledge Foundation in Sweden.

\section{REFERENCES}

Andersen, D.F.; et al., (2007). Group model building: Problem structuring, policy simulation and decision support. J. Oper. Res. Soc., 58, 691-694.

Bengtsson, M., et al., (2018). Transforming systems of consumption and production for achieving the sustainable development goals: moving beyond efficiency. Sustainability science, 13(6), 1533-1547.

Bovea, M. D., \& Pérez-Belis, V. (2012). A taxonomy of ecodesign tools for integrating environmental requirements into the product design process. Journal of Cleaner Production, 20(1), 61-71.

Broman, G. I., \& Robèrt, K. H. (2017). A framework for strategic sustainable development. Journal of Cleaner Production, 140, 17-31.

Ceschin, F., \& Gaziulusoy, I. (2016). Evolution of design for sustainability: From product design to design for system innovations and transitions. Design studies, 47, 118-163.

Coyle, R. G. (2000). Qualitative and Quantitative Modelling in System Dynamics: Some Research Questions. System Dynamics Review, 16(3), 225-244.

Dyllick, T., \& Muff, K. (2016). Clarifying the meaning of sustainable business: Introducing a typology from business-as-usual to true business sustainability. Organization \& Environment, 29(2), 156-174.

Dyllick, T., \& Rost, Z. (2017). Towards true product sustainability. Journal of Cleaner Production, 162, 346-360.

Gagnon, B., Leduc, R., \& Savard, L. (2012). From a conventional to a sustainable engineering design process: different shades of sustainability. Journal of Engineering Design, 23(1), 49-74.

Faludi, J., Hoffenson, S., Kwok, S. Y., Saidani, M., Hallstedt, S. I., Telenko, C., \& Martinez, V. (2020). A Research Roadmap for Sustainable Design Methods and Tools. Sustainability, 12(19), 8174.

Fargnoli, Mario, et al. (2018) "Product service-systems implementation: A customized framework to enhance sustainability and customer satisfaction." Journal of Cleaner Production, 188, 387-401.

Fiksel, J. (2006). Sustainability and resilience: toward a systems approach. Sustainability: Science, Practice and Policy, 2(2), 14-21.

Hallstedt, S. (2008). A foundation for sustainable product development (Doctoral dissertation, Blekinge Institute of Technology).

Hallstedt, S. I., Thompson, A. W., \& Lindahl, P. (2013). Key elements for implementing a strategic sustainability perspective in the product innovation process. Journal of Cleaner Production, 51, 277-288.

Hjorth, P., \& Bagheri, A. (2006). Navigating towards sustainable development: A system dynamics approach. Futures, 38(1), 74-92.

Hoffmann, S., Klein, J. T., \& Pohl, C. (2019). Linking transdisciplinary research projects with science and practice at large: introducing insights from knowledge utilization. Environmental Science \& Policy, 102, $36-42$.

Hojnik, J. (2018). Ecological modernization through servitization: EU regulatory support for sustainable product-service systems. Review of European, Comparative \& International Environmental Law, 27(2), $162-175$. 
Karlsson, R., \& Luttropp, C. (2006). EcoDesign: what's happening? An overview of the subject area of EcoDesign and of the papers in this special issue. Journal of cleaner production, 14(15-16), 1291-1298.

Korotkova, A. V. (2020). Eco-Movement Fridays for Future: The First Results. Mirovaia ekonomika i mezhdunarodnye otnosheniia, 64(4), 119-131.

Köhler, J., Geels, F. W., Kern, F., Markard, J., Onsongo, E., Wieczorek, A., ... \& Fünfschilling, L. (2019). An agenda for sustainability transitions research: State of the art and future directions. Environmental Innovation and Societal Transitions, 31, 1-32.

Laurenti, R., Sinha, R., Singh, J., \& Frostell, B. (2016). Towards addressing unintended environmental consequences: a planning framework. Sustainable Development, 24(1), 1-17.

Lozano, R., Ceulemans, K., Alonso-Almeida, M., Huisingh, D., Lozano, F. J., Waas, T., ... \& Hugé, J. (2015). A review of commitment and implementation of sustainable development in higher education: results from a worldwide survey. Journal of cleaner production, 108, 1-18.

Miller, T. R. (2013). Constructing sustainability science: emerging perspectives and research trajectories. Sustainability science, 8(2), 279-293.

Miedzinski, M., McDowall, W., Kemp, R., \& Türkeli, S. (2019). Inno4SD Sustainability Transition and Innovation Country Reviews. Introduction and Methodological Guidance to STIR, green. eu Report for Inno4SD network. Brussels, Belgium: Innoi4SD.

Nagaichuk, N., Shabanova, O., Tretiak, N., Marenych, A., \& Chepeliuk, H. (2020). Management of changes in the insurance industry in the conditions of climate crisis. In E3S Web of Conferences (Vol. 166, p. 13006). EDP Sciences.

Opazo-Basáez, M., Vendrell-Herrero, F., \& Bustinza, O. F. (2018). Uncovering productivity gains of digital and green servitization: Implications from the automotive industry. Sustainability, 10(5), 1524.

Pigosso, D. C., \& McAloone, T. C. (2016). Maturity-based approach for the development of environmentally sustainable product/service-systems. CIRP Journal of Manufacturing Science and Technology, 15, 33-41.

Rockström, J., Steffen, W., Noone, K., Persson, Å., Chapin III, F. S., Lambin, E., ... \& Nykvist, B. (2009). Planetary boundaries: exploring the safe operating space for humanity. Ecology and society, 14(2).

Steffen, W., Richardson, K., Rockström, J., Cornell, S. E., Fetzer, I., Bennett, E. M., ... \& Folke, C. (2015). Planetary boundaries: Guiding human development on a changing planet. Science, 347(6223).

Tata, J., \& Prasad, S. (2015). National cultural values, sustainability beliefs, and organizational initiatives. Cross Cultural Management.

Thomas, D. R. \& Hodges, I. D. (2010). Doing a literature review. In Thomas, D. R., \& Hodges, I. D. Designing and managing your research project: Core skills for social and health research (pp. 105-130). London: SAGE Publications Ltd

Vennix, J.A. (1999) Group model-building: Tackling messy problems. Syst. Dyn. Rev. 15, 379-401.

Watz, M., \& Hallstedt, S. I. (2020). Profile model for management of sustainability integration in engineering design requirements. Journal of Cleaner Production, 247, 119155. 